\title{
Nitric oxide-Important messenger in human body
}

\author{
Martina Antosova ${ }^{1}$, Jana Plevkova ${ }^{2 *}$, Anna Strapkova ${ }^{1}$, Tomas Buday ${ }^{2}$ \\ ${ }^{1}$ Department of Pharmacology Jessenius, Faculty of Medicine, Comenius University, Bratislava, Slovakia \\ ${ }^{2}$ Department of Pathological Physiology Jessenius, Faculty of Medicine, Comenius University, Bratislava, Slovakia \\ Email: ${ }^{3}$ iplevkova@gmail.com, antosova@j,jmed.uniba.sk
}

Received 20 January 2012; revised 7 March 2012; accepted 20 March 2012

\begin{abstract}
General idea of this comprehensive review is to summarize information about the role of nitric oxide in the human body-cardiovascular, respiratory, urgenital, gut, NO and immune system, however, NO signaling has a role also in musculoskeletal system, even in bones. NO in the past had been recognized as a molecule relevant to air pollution. In 1980 Furchgott and Zawadzki identified new messenger molecule within the endothelial cells with vasodilating potential and they named it endothelium derived relaxing factor (EDRF). Seven years later the role of NO as a relaxing factor was definitely proven. The fact of gas, being produced by cells, crossing membranes of neighboring cells and having a character of signal brought a brand new insight to the signaling physiology. The breakthrough in the NO history was in 1992, when it was assigned as "molecule of the year". Role of NO was defined mainly in the cardiovascular system, but as the research expanded, the ultimate function, and mechanism of action, dual effect of NO had been identified in all systems of human body. NO in low concentrations considerably regulates the physiological functions, but in high concentration may contribute to the pathogenetic process. Knowledge the physiology of NO signaling cascades could have clinical application, mainly considering therapeutic potential of NO donors, or antagonists of NO-synthases. This molecule has undoubtedly huge future potential.
\end{abstract}

Keywords: Nitric Oxide; Physiology; Signaling

\section{NITRIC OXIDE-MECHANISM OF ACTION}

Nitric oxide (NO) has basically dual action in biological systems. Low optimal concentrations regulate a lot of physiological processes however overproduction of nitric oxide takes role in pathogenesis of many diseases [1].

"Corresponding author.
Stimulation of isoforms of NO synthase (NOS) leads to production of $\mathrm{NO}$, which could be in form of $\mathrm{NO} \cdot$, or chemically attached to thiols-SH groups. The action of NO could be either direct or indirect. Direct action is mediated by activation of soluble guanylyl cyclase (GC-S) with production of second messenger cyclic guanosine monophosphate (cGMP), or direct activation of ion channels. Indirect effect is usually mediated by the production of reactive oxygen species (ROS) [2]. After production inside the cells, NO is released to their neighborhood and diffuses mainly across the cell membranes of target cells as a signal influencing biological processes. Then, NO is attached to the $\mathrm{Fe}^{2+}$ of the hem part of soluble guanylyl cyclase, leading to activation of this enzyme. Guanylyl cyclase turns guanosine triphosphate (GTP) to cGMP thus activating cGMP dependent proteinkinases. These further catalyze phosphorylation of different proteins, activation or inhibition of some ion channels and regulate activity of phosphodiesterases [3]. The consequences of these processes are different biological actions like relaxation of smooth muscle cells, influence of endothelial permeability, cardial protection, neuronal plasticity, improvement of cognitive functions and many others. Complexity of the NO action and understanding of this signal cascade it critical for research of novel pharmacological applications [4]. Similar mechanism is employed in the action of NO released from thiol group.

Recent studies revealed that NO is capable to activate potassium channels, mainly calcium dependent potassium channels $\mathrm{BK}_{\mathrm{Ca}}$ and $\mathrm{ATP}$ sensitive potassium channel $\mathrm{K}_{\mathrm{ATP}}$ in smooth muscle, neurons, endothelial cells etc., which are cGMP independent processes. After activation of these channels membrane becomes hyperpolarized with decrease of $\mathrm{Ca}^{2+}$ ions, which leads to relaxation of vascular or bronchial smooth muscles [5].

Indirect action of NO had been named by many authors as cytotoxic. They could be mediated by oxidative stress and nitrosative stress. While oxidative stress is involved in pathogenesis of inflammatory diseases, nitrosative stress could be responsible for production of molecules with carcinogenic potential—nitrosamines. Production of 
oxygen and nitrogen species is under control of amount and availability of NO, superoxide, manganese, superoxide dismutase and other oxidants. The main consequence of this reaction is damage of lipids, proteins and DNA leading to multiple dysfunctions at molecular, cellular and finally tissue level.

Regarding indirect action of NO it is also important to say that NO modulates gene expression, via modulation of transcription factors. The most important of them is nuclear factor $\kappa \mathrm{B}(\mathrm{NF} \kappa \mathrm{B})$. This factor regulates transcription of many pro-inflammatory molecules, enzymes (iNOS and COX-2), cytokines (IL- $1 \beta$, TNF- $\alpha$ and IL-6) and chemokines (IL-8). Activation of $\mathrm{NF} \kappa \mathrm{B}$ may induce processes with increased expression of inductive NOsynthase (iNOS), increased production of NO and other factors that may be responsible for tissue damage in case of chronic inflammatory processes.

\section{MAIN EFFECTS OF NO}

In human body low level of NO regulates many physiological functions. At the other hand, at pathological conditions high concentrations of NO could be either desirable (antibacterial, antiparasitic, antiviral effects) or could have adverse effects-mainly pro-inflammatory action. Therefore it is necessary to know specifically the action of NO in different systems to minimize adverse effects, but maximize desirable effects of NO for pharmacological applications.

\subsection{Nitric Oxide and Nervous System}

\subsubsection{Central Nervous System}

Nitric oxide influences considerably central and peripheral nervous system. It is one of the most important neurotransmitters. Because NO is gas, therefore is not stored in synaptic vesicles, but synthesized accordingly to the requirements, with rapid diffusion to neighboring neurons. Its role had been documented at physiological and also pathological processes, and the role of nitric oxide could be explained as neuromodulatory, neuroprotective, but also neurotoxic at some specific circumstances.

In central nervous system is nitric oxide synthesized mainly by neuronal isoform od NO-synthase (nNOS). This enzyme is expressed in the cerebral cortex, claustrum, olfactory regions, striatum, amygdale, hippocampus, hypothalamus, thalamus and cerebellum. Neuronal isoforms of NOS had been identified also in astrocytes, and cerebral vessels [6].

Basic functions of NO in central nervous system are regulation of neuronal morphogenesis, regulation of sexual and aggressive behaviors, food intake, pain perception, short-term and long-term synaptic plasticity in sleep control and regulation, neurosecretion and cerebral blood flow.
It has been also documented that NO cooperates with NMDA receptors, and is capable to potentiate synaptic transmission via NMDA receptors. NMDA activates production and release of NO in experimental conditions, and it may mediate responses to excitatory amino acids (aspartate, glutamate). Neurotoxic effect is mediated also by the production of reactive oxygen species, mainly, superoxide anion.

Nitric oxide participates also in the food intake regulation. Repeated administration of substances which inhibit production of NO, decrease appetite and also body weight in obese experimental animals.

At pathological conditions, the effects of nitric oxide could be responsible for neuronal damage and neurodegenerative diseases such as Parkinson disease, Alzheimer dementia, Huntington chorea etc. In these mentioned disease NO plays a role mainly in processes like tyrosine nitrosylation, excitotoxicity, inhibition of mitochondrial respiration chain, fragmentation of sub cellular organelles etc. [7].

\subsubsection{Peripheral Nervous System}

Nerve fibers producing and releasing NO do not belong to the sympathetic and parasympathetic branches, but they form distinct population of non-adrenergic non-cholinergic fibers (NANC). This system could be categorized according preferential activity to excitatory (eNANC) and inhibitory (iNANC). Nitric oxide is main mediator for iNANC system. Within peripheral nervous system nNOS is localized mainly in iNANC nerves of airways, gastrointestinal and urogenital tract. In these systems NO regulates mainly relaxation of smooth muscles, including vascular muscles. At physiological conditions NO via NANC system regulates blood flow, bronchial tone and regulates inflammatory processes. Its activity depends on many factors including activity of synthesizing enzymes, cofactors, level of oxidative stress, and activity of antioxidative molecules [8].

At pathological conditions NO could induce neuronal block (multiple sclerosis), or induce absolute inability for transmission of action potentials in myelinated and unmyelinated fibers.

\subsection{Cardiovascular System}

\subsubsection{Vessels}

The role of nitric oxide in cardiovascular system is of high interest at the level of basic research and also at the level of clinical cardiology. Majority of authors agree to the fact that NO is strong and effective molecule, critically useful in prevention and treatment of ischemic heart disease.

One of the physiological effects of NO is vasodilatation which had been documented in experimental animal models and also in humans. The effect was demonstrated 
using inhibitors of NOS inducing vasoconstriction in vitro and hypertensive reaction in vivo. In cardiovascular system, NO is produced mainly by the endothelial isoform of NOS (eNOS). Basal release of NO from L-arginine plays important role in regulation of blood flow and blood pressure. NO is slowly, but continually released in arterial part of cardiovascular system, and also regulates tonus of small arteries and venules within microcirculation [9]. Main stimuli responsible for NO release are shear stress and distension of the vessels. The role of NO in regulation of the vascular tone is well defined, based on the conception describing production of NO in endothelial cells with subsequent diffusion to the media. Then NO activates guanylate cyclase thus increasing concentration of cGMP in muscle cells, decreasing intracellular concentration of $\mathrm{Ca}^{2+}$ leading to their relaxation. Increase of cGMP could be mediated also via activation of proteinkinase $\mathrm{G}$ and phosphorylation of heat shock protein (HsP 20).

Endothelial cells are equipped with a plenty of receptors relevant for variety of chemical signals present in the blood. They are capable to respond to the changes of physical parameters such as elasticity, pressure or viscosity. Relatively rapid adaptation of blood vessels to these stimuli is mediated via production and release of NO. Basal production of NO participates in regulation of blood flow in brain vessels, coronary circulation, gastrointestinal system and kidneys. This sort of regulation could be mediated also via direct opening of calcium channels at endothelial cells membrane, which leads to $\mathrm{Ca}^{2+}$ dependent activation of eNOS with subsequent increase of local NO production [10].
Main effects of nitric oxide in cardiovascular system are summarized at Figure 1.

Vascular tone regulation and endothelial dysfunction may appear as the consequence of decreased biological availability of nitric oxide. This phenomenon is present in subjects with metabolic diseases such diabetes mellitus, hypercholesterolemia, in subjects with hypertension, smokers, and it is one of the critical steps in development of atherosclerosis. Endothelial dysfunction may induce local deficit of NO, which may in turn lead to adhesion and aggregation of thrombocytes. It may also lead to dysregulation of vascular lumen, leading to vasoconstriction, even spasm with turbulent blood flow, adhesion of cells, and infiltration of vessel wall by lipid particles. It had been documented in laboratory animals that inhibition of NO production leads to faster growing of atherosclerotic plaques. At the other hand, overproduction of NO may lead to profound vascular relaxation with pressure drop and tissue hypoperfusion. This mechanism may be involved in pathogenesis of septic shock and multiple organ dysfunctions in subjects with SIRS or sepsis [11].

\subsubsection{Heart}

The role of NO in heart is less defined. There are studies regarding the role of $\mathrm{NO}$ in heart regulation, but they are sharing conflicting evidence. All three isoforms of NOS had been identified in heart. They are localized in endothelial cells, or directly inside cardiomyocytes. Neuronal isoform is present in sinus node as an important modulator of pre-synaptic influence of the vagus nerve as nitric oxide facilitates acetylcholine release.

The effect of NO on heart depends considerably on the

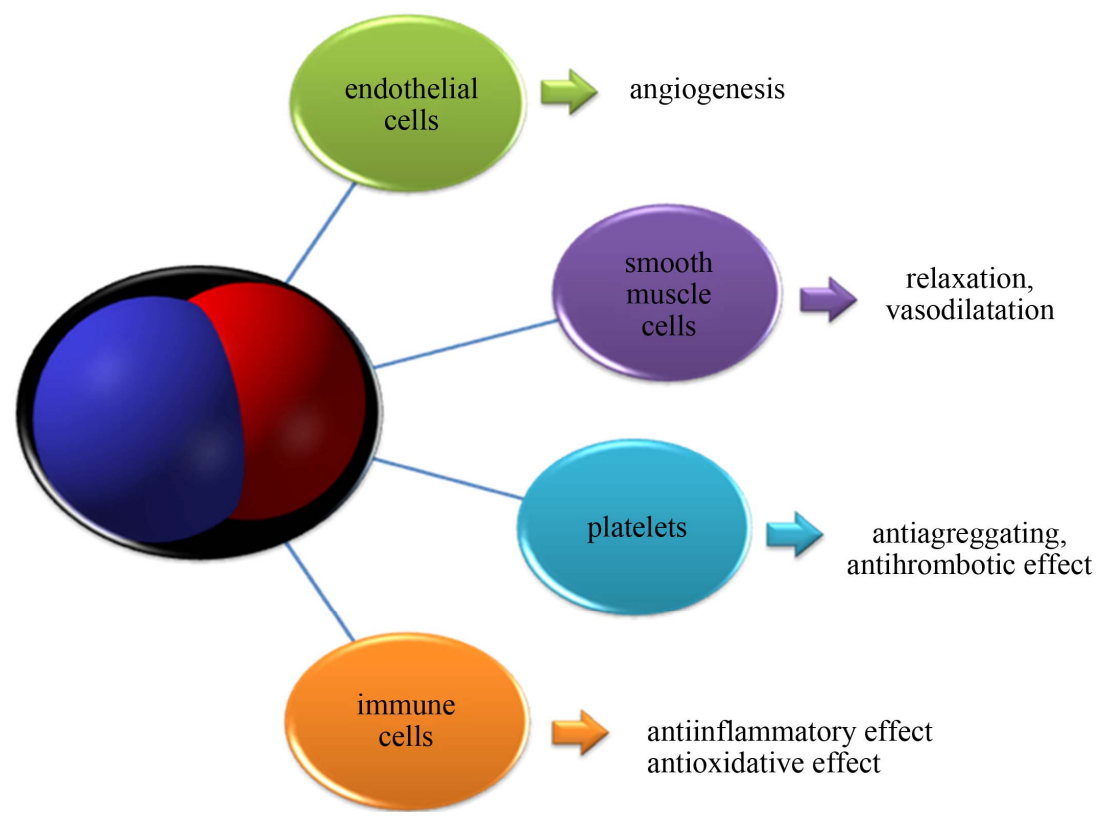

Figure 1. Main action of NO in vascular system. 
NOS isoform which had been activated. Similarly, like in other systems constitutive isoforms are active at physiological conditions, whereas pathological conditions increase expression of inductive isoform.

Effects of NO produced at physiological conditions are related to the coronary circulation (vasodilatation, rise of coronary blood flow, antithrombotic, anti-inflammatory action, improvement of endothelial dysfunction), cardiomyocytes (decreased apoptosis, decrease of oxygen consumption), myocardium (fetal and postnatal growth, antihypertrophic effect, rise of ischemic tolerance), conductive system (negative inotropic and chronotropic effect). They are mediated via NO/cGMP pathway and also by modulation of local mitochondrial metabolism, regulation of calcium ions in cardiomyocytes and regulation of autonomic nervous system influences [12].

Data about pathological and adverse effects of NO in myocardium are conflicting, however many papers agree to the mechanisms being employed in this process. They mainly discuss production of ROS, leading to enhanced apoptosis and necrosis of cardiomyocytes. It was also found that fluctuation of NO level in heart may participate in onset of arrhythmias, myocardial damage after ischemia and onset and progression of endothelial dysfunction in coronary vessels [13].

\subsection{Respiratory System}

Endogenous and also exogenous NO has positive effects in prevention of smooth muscle contraction in airways. Bronchodilatation may be also positively influenced by the action of S-nitrosothiols as donors of NO. Regulation of bronchomotoric tonus is the main function of $\mathrm{NO}$ in airways [14]. Other effects of NO in respiratory system are summarized in Table $\mathbf{1}$.

Release of NO by the endothelial cells in the pulmonary circulation regulates the basal vascular tonus and prevents vasoconstriction, however the effect of nitric oxide on pulmonary microcirculation and vascular permeability is not completely elucidated [15]. It is known that nitric oxide is produced in lungs by both constitutive isoforms of NOS. Nitric oxide may contribute to the angiogenesis and lung growth during fetal development and increased activity of both constitutive isoforms may improve postpartal adaptation of the newborn respiratory system [16]. Inhibition of NO production and release leads to decrease of surfactant production via drop of cGMP. These studies support the hypothesis that low concentrations of NO participates in regulation of surfactant release via cGMP dependent mechanisms and activation of proteinkinase G. Overproduction of NO and subsequent production of ROS may inhibit the function of surfactant by the peroxidation of lipids and damage of the surfactant proteins.

Endogenous NO stimulates activity of submucosal glands with increased mucus output. These findings had been proven by the administration of NO donors which considerably increased the mucus output and also by the NOS inhibitors, which suppressed glandular activity. Cilliary motility is important airway defensive mechanism, which could be up-regulated by the activity of inflammatory cytokines. Stimulatory effect of cytokines had been suppressed by administration of NOS inhibitors and activated by NO donor L-arginine. These evidences speak for NO being involved in regulation of mucociliary transport [17]. Pathogenesis of airway diseases (including allergic diseases) is also modulated by nitric oxide at the level of immune system, specifically at the level of signaling between $\mathrm{T}$ lymphocytes and macrophages. NO modulates production and function of immune cells released cytokines, chemokines, and growth factors. Final effect of nitric oxide in airways (protective or toxic) depends on the type of activated isoforms of NOS, concentration of NO, the site of production and finally its reaction with the other substrates [18].

From pathological effects of nitric oxide it is important to mention its role in bronchial smooth muscle

Table 1. Physiological and pathological effects of NO in respiratory system.

\begin{tabular}{|c|c|c|}
\hline Target & Physiology & Pathology \\
\hline Airway smooth muscle & Relaxation-bronchodilatation & $\begin{array}{l}\text { - } \uparrow \downarrow \text { Hyperreactivity depending on activity of iNOS } \\
\text { - Proliferation, airway narrowing }\end{array}$ \\
\hline \multirow[t]{2}{*}{ Vessels } & Relaxation-vasodilatation & $\begin{array}{l}\text { - } \uparrow \text { Washout of bronchoconstrictory mediators } \\
\text { - } \uparrow \text { Exudation and edema }\end{array}$ \\
\hline & Anti-inflammatory effects & Pro-inflammatory effects \\
\hline \multirow[t]{2}{*}{ Immune system } & $\begin{array}{l}-\downarrow \text { Function of leukocytes } \\
-\downarrow \text { Permeability of endothelial cells } \\
\text { - } \downarrow \text { Activation of mast cells }\end{array}$ & $\begin{array}{l}\text { - } \uparrow \text { Eosinophilic infiltration } \\
\text { - } \uparrow \text { Vascular permeability } \\
\text { - } \uparrow \text { Airway narrowing }\end{array}$ \\
\hline & Antiviral, antibacterial and antiparasitic effect & \\
\hline \multirow[b]{2}{*}{ Epithelium } & Regulation of mucociliary transport & Regulation of mucociliary transport \\
\hline & $\begin{array}{l}-\uparrow \text { Rate of cilliary beat } \\
\bullet \downarrow \downarrow \text { Mucus viscosity }\end{array}$ & $\downarrow \uparrow$ Mucus output \\
\hline
\end{tabular}


proliferation leading to airway narrowing and limitation of expiratory airflow. The role of NO had been documented in pathogenesis of asthma, chronic obstructive pulmonary disease, primary cilliary dyskinesis and also acute respiratory diseases.

\subsection{Gastrointestinal Tract}

Main physiological functions of gastrointestinal tract include digestion, absorption and excretion. Even in these processes nitric oxide has its position. In the GIT it primarily acts as a neurotransmitter. It is released by peripheral nervous system, represented by iNANC nerve fibers. Nitric oxide was detected in myenteric plexus of stomach and intestines, the lower esophageal, ileocolic and internal anal sphincter and its release under physiological conditions is responsible for adaptive dilatation of the stomach, regulation of peristalsis and stimulation of mucus secretion into the gut. These effects of NO are mediated mainly by activating GC-S, but also 5-HT receptors [19].

Several works suggest that nitric oxide is the most important inhibitory neurotransmitter in the intestinal NANC. It inhibits gastrointestinal motility and controls the activities of sphincters, e.g. lower esophageal sphincter, sphincter of Oddi, or anal sphincter. The inhibition of endogenous NO production enhances contractility of sphincters, while when increased by substitution of NO reduces contractility of sphincters. Substances modulating the homeostasis of NO positively affect sphincter contraction in the distal esophagus that could be used for example in the treatment of gastro esophageal reflux disease [20].

Gastrointestinal tract is well protected from exposure to irritating foods (e.g. alcohol), but also from adverse impact of increased endogenous secretions (acid, proteolytic enzymes, bile). Mucosal barrier layer is formed by intestinal epithelial cells and non-specific protective substances such as mucus and lysozyme. These substances also include NO. It regulates mucosal blood perfusion, reduces adherence of leukocytes, inhibits the activation of mast cells and stimulates the secretion of gastric mucus [21].

Another of the roles of NO is in the mucosal immune response, where nitric oxide has a very important defensive function. Induction of iNOS in the epithelium has been demonstrated in inflammatory bowel disease.

Currently, there are also some interesting theories about the involvement of $\mathrm{NO}$ in the process of tumor formation in gastrointestinal tract. Again, here we encounter a dual effect-pro-tumor in conjunction angiogenesis and other hand anti-carcinogenic effect in mean of cytotoxic damage of tumor cells [22]. Overview of main effects of nitric oxide in gastrointestinal tract shows the following Table 2.

\subsection{Urogenital System}

\subsubsection{Urinary System}

The growth of literature in this area shows several effects of nitric oxide in the renal physiology and in pathophysiology. In immunohistochemical studies it was shown that in the urogenital system are all three isoforms of NOS. eNOS is present mainly in the microvasculature, glomerular

Table 2. Physiological and pathological effects of nitric oxide in GIT.

\begin{tabular}{|c|c|c|}
\hline Target & Physiology & Patophysiology \\
\hline \multirow[b]{2}{*}{ Smooth muscle } & Relaxation-main neurotransmitter of NANC & $\begin{array}{l}\text { - Spasm of esophagus } \\
\text { - Gastroparesis } \\
\text { - Chronic intestinal pseudoobstruction }\end{array}$ \\
\hline & Regulation of blood flow in the mucosa & $\begin{array}{l}\text { - Ileus } \\
\text { - Toxic megacolon } \\
\text { - Gastric ulcers }\end{array}$ \\
\hline \multirow[t]{2}{*}{ Sphincters } & Relaxation & $\begin{array}{l}\text { - GERD } \\
\text { - Achalasia } \\
\text { - Pylorostenosis } \\
\text { - Dysfunction of Oddi sphincter } \\
\text { - Hirsprung disease } \\
\text { - Fissure ani }\end{array}$ \\
\hline & Anti-inflammatory effect & Pro-inflammatory effect \\
\hline Immune system & $\begin{array}{l}\text { - Stabilization of mast cells } \\
\text { - Inhibition of Th1 cytokines production } \\
\text { - Bacteriostatic effect } \\
\text { - Anticancer effect }\end{array}$ & $\begin{array}{l}\text { - Production of ROS } \\
\text { - Inflammatory diseases } \\
\text { - Microscopic colitis } \\
\text { - Diverticulitis } \\
\text { - Infectious diarrhea }\end{array}$ \\
\hline Epithelium & $\begin{array}{l}\text { - Increased production of protective mucus } \\
\text { - Inhibition of platelets aggregation and adhesion } \\
\text { - Defense of mucosa against inflammation and damage }\end{array}$ & $\begin{array}{l}\text { - } \downarrow \uparrow \text { Secretion of chloride ions } \\
\text { - } \uparrow \text { Permeability at sepsis } \\
\text { - Intestinal metaplasia } \\
\text { - Polyps } \\
\text { - Tumors }\end{array}$ \\
\hline
\end{tabular}


endothelial cells, proximal tubule, loop of Henle and collecting duct. Neuronal isoform is also in the macula densa, collecting duct principal cells and pelvic nerves. Functional studies confirmed the presence of iNOS [23].

Physiological levels of NO regulate glomerular hemodynamic, medullar rennin secretion, tubuloglomerular feed-back and extracellular fluid volume. Based on available literature data we can conclude that nitric oxide in the kidney contributes to the regulation of micro- and macro vascular hemodynamic, stimulates resorption of sodium, $\mathrm{HCO}^{3-}$ and water in proximal tubules, stimulates acidification in the proximal tubule, sodium reabsorption, inhibits $\mathrm{HCO}^{3-}$ and water reabsorbtion in the distal tubule, $\mathrm{Na}^{+}$reabsorbing in the collecting ducts and inhibits $\mathrm{H}^{+}$-ATPase in collecting ducts. Result of this action is to increase blood flow and kidney glomerular filtration rate, diuresis and natriuresis.

In pathological conditions, e.g. under inflammation, the superoxide anion, peroxynitrite and other radicals are produced, which may contribute to autoimmune glomerulonephritis or post-ischemic kidney damage. In connection with pathology, NO is found in acute as well as chronic renal impairment. The experiments with administration of NO synthase inhibitors in renal disease were interesting as well. The effect was biphasic. While in the acute phase, the renoprotective effect had been observed, chronic administration of inhibitors accelerated renal damage. These results compel further research into the physiological effects of NO in the kidney [24].

\subsubsection{Reproductive System}

Nitric oxide participates in the regulation of female and male reproductive system. Likewise as in other systems, here is NO involved in physiological and pathophysiological processes and influence on its activity may be of great clinical importance (Figure 2).

In ovaries NO regulates follicle maturation and ovulation. NO levels correlate with estrogen levels. Estrogens as important hormonal stimuli activate mainly constitutive isoform-eNOS and nNOS. This positive relationship was confirmed by application of NOS inhibitors, which prevent ovulation in experimental animals. Interesting is also the position of iNOS. Its activity is not stimulated by inflammation, but rather responds to the synthesis of steroid hormones. Physiological significance of iNOS expression in the ovaries remains unclear so far. It is possible that under conditions of continuous development and growth of follicles acts iNOS and its active mediators as a regulatory growth molecule [25]. It is thought that nitric oxide plays an important functional role in promoting fertilization in the fallopian tube. Basal release of NO stimulates the movement of sperm. It regulates the contraction of the oviduct and can to some extent affect the kinetics of oviduct cilia [26].

All isoforms of NO synthase were also detected in uterine epithelium, endometrial stromal cells and myometrial cells. The uterus is an organ which undergoes important structural changes during menstruation and pregnancy. Given that NO regulates smooth muscle contractility and

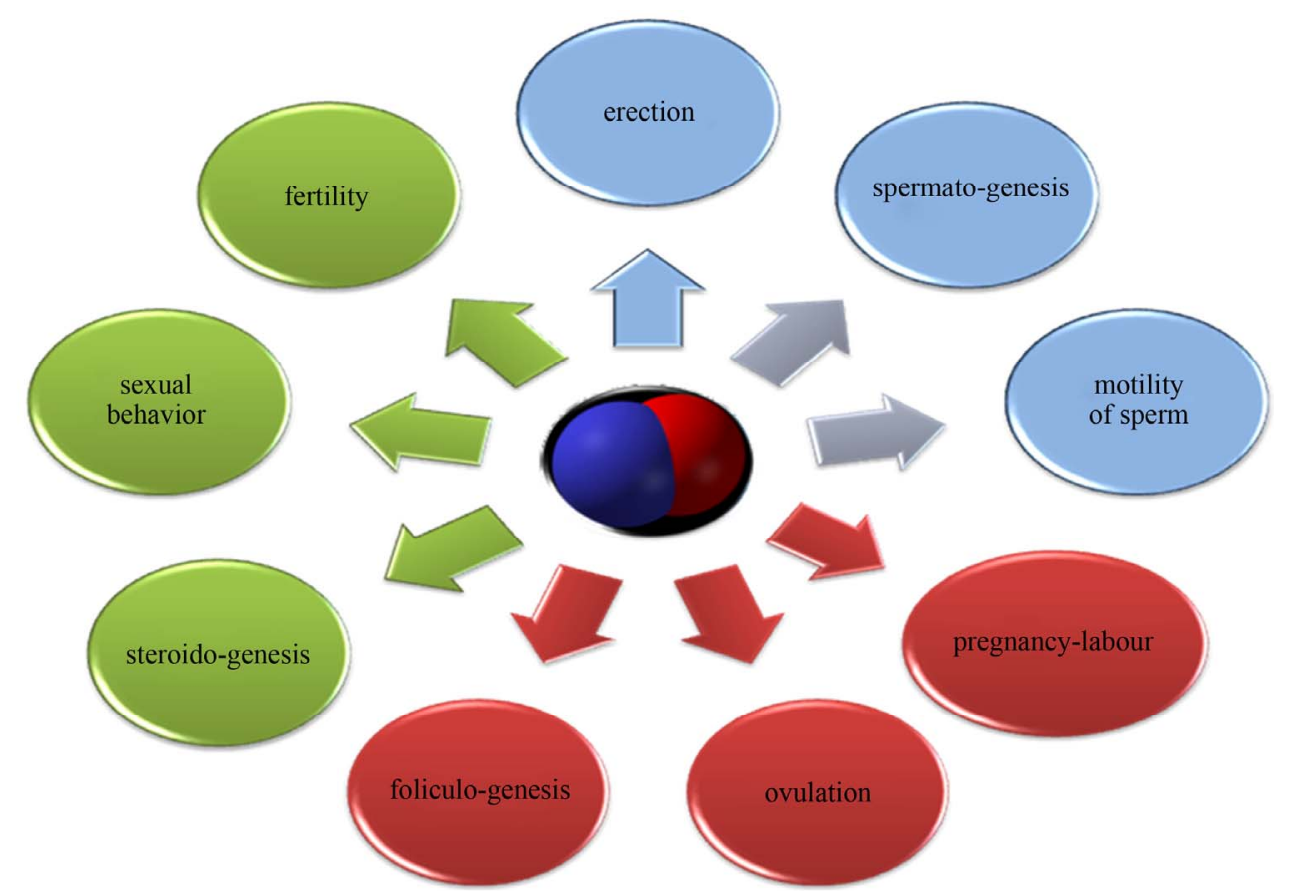

Figure 2. Basic physiological processes in the reproductive system affected by nitric oxide (blue-men, red-women, green - in both sexes). 
thus the spontaneous contraction and dilation of the uterus during pregnancy, the role of NO in this field has gained much attention. Based on literature data, we can say that nitric oxide plays an important regulatory position both during pregnancy and childbirth [27].

Its deficiency is associated with conditions of preeclampsia with hypertension and substitution of NO donors is recommended to pregnant women with the threat of premature birth.

One of the best described physiological effects of NO in the male reproductive system is the regulation of erection by NANC neurotransmission. Nitric oxide can thus be regarded as a physiological mediator of erection. It is controlled either through a second messenger-cGMP or indirectly by NO independent mechanisms. The different isoforms of NOS have been identified only in NANC (nNOS) but also in endothelium of corpora cavernosa of the penis (eNOS) [28].

Testicles are rich of both L-arginine and NO. Constitutive NO-synthase was detected in Leidigo cells, Sertoli cells and endothelial cells of the testis. These findings suggest the involvement of NO-cGMP signaling pathway in the regulatory function of the testes, particularly in spermatogenesis in all its phases. The effect on the synthesis of steroids is interesting, where $\mathrm{NO}$ acts as autocrine/ paracrine mediator. In addition to spermatogenesis, it modulates blood flow, cell permeability and myofibroblast contractility in testis [29].
As already described for the female reproductive system, nitric oxide affects sperm motility. Low concentrations of NO accelerate the movement; medium or high concentration of nitric oxide reduces their mobility, or completely inhibits. In human spermatozoa, however, no isoform of NO-synthase appears, modulation is, therefore, not yet well understood. It is possible that inhibition of movement occurs only in a woman's fallopian tube, where it triggers the immune response after ejaculation similar to bacterial infection or organ transplantation.

\subsection{Immune System}

According to some authors the formation of nitric oxide is main function of the immune system, which contains the most active inductive NOS isoform. Nitric oxide generated by iNOS has antimicrobial, antitumor, cytostatic and cytotoxic effects that are associated mainly with the production of free radicals (superoxide, peroxynitrite). These cause the inactivation of enzymes containing iron and various modifications of proteins leading to a cytostatic or cytotoxic effect against pathogens [30]. The cytotoxic effect of NO against tumor cells was also observed. Increased iNOS activity plays a protective role in various bacterial and parasitic infections and in response to inflammation. Nitric oxide controls many processes in immune system. These include differentiation, proliferation and apoptosis of immune cells, production of

Table 3. Main effects of NO in the immune system.

\begin{tabular}{|c|c|c|}
\hline Basic effect & Propagator cell of IS & Molecular mechanism \\
\hline $\begin{array}{l}\text { Antimicrobial effect-kill or reduce replication of } \\
\text { infectious agents (viruses, bacteria, parasites and fungi) }\end{array}$ & $\begin{array}{l}\text { - Macrophages } \\
\text { - Microglia, astroglia } \\
\text { - Neutrophils } \\
\text { - Eosinophils } \\
\text { - Fibroblasts } \\
\text { - Cells of endothelial } \\
\text { - And epithelial }\end{array}$ & $\begin{array}{l}\text { - NO direct effect on pathogen } \\
\text { - Indirect effect-via ROS }\end{array}$ \\
\hline $\begin{array}{l}\text { Antitumor effect-killing or slowing the growth } \\
\text { of tumor cells }\end{array}$ & $\begin{array}{l}\text { - Macrophages, } \\
\text { - Eosinophils, }\end{array}$ & $\begin{array}{l}\text { - Inhibition of enzymes essential for tumor growth } \\
\text { - Suspension of growth through iNOS depletion of L-arginine } \\
\text { - Increased apoptosis } \\
\text { - Sensitize tumor cells to TNF-induced cytotoxicity }\end{array}$ \\
\hline $\begin{array}{l}\text { Immunopathological effect-in terms of damage to } \\
\text { tissue necrosis or fibrosis of parenchyma }\end{array}$ & $\begin{array}{l}\text { - Macrophages, } \\
\text { - Microglia, astroglia } \\
\text { - Keratinocytes } \\
\text { - Mesangial cell }\end{array}$ & $\begin{array}{l}\text { - Apoptosis of parenchyma cell } \\
\text { - Degradation of extracellular matrix } \\
\text { - Proliferation of mesenchyma cells } \\
\text { - Regulating influx of inflammatory cells through regulation of } \\
\text { cytokine }\end{array}$ \\
\hline $\begin{array}{l}\text { Anti-inflammatory effects-immunosuppression in } \\
\text { terms of inhibition of T and B lymphocytes, antibody } \\
\text { production and inhibition of extravasation, chemotaxis } \\
\text { and adhesion of leukocytes }\end{array}$ & - Macrophages & $\begin{array}{l}\text { - Apoptosis of T cell } \\
\text { - Down-regulation of co-stimulatory cytokine molecules } \\
\text { - Disruption of signaling cascades and transcription factors } \\
\text { - Inhibition of DNA synthesis } \\
\text { - Down-regulation of adhesion molecules and chemokines }\end{array}$ \\
\hline $\begin{array}{l}\text { Production and function of modulation of cytokines, } \\
\text { chemokines and growth factors-up and } \\
\text { down-regulation for example. IL- } 1 \text {, IL- } 6 \text {, IL- } 8 \text {, IL-10, } \\
\text { IL-12, IFN- } \gamma \text {, TNF- } \alpha \text {, TGF- } \beta \text { and the like }\end{array}$ & $\begin{array}{l}\text { - Macrophages } \\
\text { - T lymphocytes } \\
\text { - Endothelial cells } \\
\text { - Fibroblasts }\end{array}$ & $\begin{array}{l}\text { - Modulation of signaling cascades (MAP kinases, caspases, } \\
\text { protein phosphatases, etc.) and transcription factors (NF- } \kappa \mathrm{B} \text {, } \\
\text { Sp1, etc.) } \\
\text { - Protein regulation of mRNA stability and translation } \\
\text { - Of cytokine modulation of latent precursor enzymes and their } \\
\text { complexes }\end{array}$ \\
\hline
\end{tabular}


cytokines and other mediators, modulation of leukocyte adhesion and chemotaxis, modulation of co-stimulatory and adhesion molecules (vascular cell adhesion molecule-1 (VCAM-1), intercellular adhesion molecule-1 (ICAM-1), E-selectin (CD62E) and P-selectin (CD62P), synthesis and deposition of extracellular material components, immunomodulation and nonspecific and specific immune responses, antibacterial, antiviral, antitumor effect, etc. [31] (Table 3).

In specific immune response the $\mathrm{T}$ type lymphocytes (LyT) play significant role providing humoral type of response. They have several subtypes, which, when activated produce lymphokines that regulate other immune cells. Th-1 lymphocytes produce IL-2, IL-12, TNF- $\alpha$ and interferon gamma (IFN- $\gamma$ ), Th-2 cells produce IL-4, IL-5, IL-6, IL-10 and IL-13. There is evidence that lymphokines produced by LyTh-1 increase production of NO, whereas lymphokines produced by LyTh-2 decrease the NO production. On the other hand, nitric oxide can inhibit Th-1 lymphokines but has no direct impact on Th-2 lymphokines production. The balance between production of Th-1 and Th- 2 cytokines is similar to competitive processing of L-arginine by iNOS and arginase.

Cytotoxic effect of NO is not only expressed in immune processes, but in some cases acting nitric oxide as an important pro-inflammatory molecule. Unless there is a causative factor in the form of infectious agents, may be overproduction of $\mathrm{NO}$ one possibility of autoimmune diseases such as rheumatoid arthritis, autoimmune diabetes, multiple sclerosis, systemic lupus, etc. These levels are also involved in the process of transplant rejection and pathogenic process of septic shock or chronic inflammatory diseases.

The fact that NO regulates apoptosis of immune cells may contribute to the onset and progression of autoimmune diseases, and also changed immunological surveillance and lack of cytotoxic effect against tumor cells may lead to cancer.

\section{CONCLUSIONS}

The role of nitric oxide in the human body is under the scope of intensive research at the level of basic experimental research and also at the level of clinical studies. As it could be seen from this review, almost all systems of human body are carefully studied regarding the role of NO in regulations, basically under normal conditions, and also during diseases, as it is obvious that NO has different roles when comparing normal physiological processes versus pathological processes. Identification of pathways for NO synthesis, then identification of signaling cascades and their cooperation with other messenger systems making this molecule so much interesting and useful from the standpoint of potential clinical applications.
Donors of NO have therapeutic significance for example in patients suffering from ischemic heart disease, bacterial infection and wound healing. Then, measurement of exhaled NO is useful tool for diagnosis of airway inflammation.

Broad brush data collected and analyzed in this review are an evidence that intensive research of nitric oxide, and nitric oxide associated pathways would have more clinical applications in due time.

\section{REFERENCES}

[1] Anggard, E. (1994) Nitric oxide: Mediator, murderer, and medicine. Lancet, 343, 1199-1206. doi:10.1016/S0140-6736(94)92405-8

[2] Carvajal, J.A., Germain, A.M., Huidobro-Toro, J.P. and Weiner, C.P. (2000) Molecular mechanism of cGMPmediated smooth muscle relaxation. Journal of Cellular Physiology, 184, 409-420.

doi:10.1002/1097-4652(200009)184:3<409::AID-JCP16 $>3.0 . \mathrm{CO} ; 2-\mathrm{K}$

[3] Francis, S.H., Busch, J.L., Corbin, J.D. and Sibley, D. (2010) cGMP-dependent protein kinases and cGMP phosphodiesterases in nitric oxide and cGMP action. Pharmacological Reviews, 62, 525-563. doi:10.1124/pr.110.002907

[4] Jerca, L., Jerca, O., Mancas, G., Constantinescu, I. and Lupusoru, R. (2002) Mechanism of action and biochemical effects of nitric oxide (NO). The Journal of Preventive Medicine, 10, 35-45.

[5] Garcia-Calvo, M., Knaus, H.G., McManus, O.B., Giangiacam, K.M., Kaczorowski, G.J. and Garcia, M.L. (1994) Purification and reconstitution of the high-conductance, calcium activated potassium channel from tracheal smooth muscle. Journal of Biological Chemistry, 269, 676-682.

[6] Knott, A.B. and Bossy-Wetzel, E. (2009) Nitric Oxide in Health and Disease of the Nervous System. Antioxidants \& Redox Signaling, 11, 541-554.

[7] Calabrese, V., Mancuso, C., Calvani, C., Rizzarelli, E., Butterfield, D. and Stella, A.M. (2007) Nitric oxide in the central nervous system: Neuroprotection versus neurotoxicity. Nature Reviews Neuroscience, 10, 766-775. doi:10.1038/nrn2214

[8] Bult, H., Boeckxstaens, G.E., Pelckmans, P.A., Jordaens, F.H., Van Maercke, Y.M. and Herman, A.G. (1990) Nitric oxide as an inhibitory non-adrenergic noncholinergic neurotransmitter. Nature, 345, 346-347. doi: $10.1038 / 345346 \mathrm{a} 0$

[9] Hollenberg, N.K. (2006) Organ systems dependent on nitric oxide and the potential for nitric oxide-targeted therapies in related diseases. The Journal of Clinical Hypertension, 12, 63-73. doi:10.1111/j.1524-6175.2006.06042.x

[10] Ignarro, L.J. (2002) Nitric oxide as a unique signaling molecule in the vascular system: A historical overview. Journal of Physiology and Pharmacology, 53, 503-514.

[11] Bae, E.H., Kim, I.J., Ma, S.K., Lee, J.U. and Kim, S.W. 
(2011) Altered regulation of renal nitric oxide and atrial natriuretic peptide systems in lipopolysaccharide-induced kidney injury. Korean Journal of Physiology \& Pharmacology, 15, 273-277. doi:10.4196/kipp.2011.15.5.273

[12] Strijdom, H., Chamane, N. and Lochner, A. (2009) Nitric oxide in the cardiovascular system: A simple molecule with complex actions. Cardiovascular Journal of Africa, 20, 303-310.

[13] Lv, L., Jiang, S.S., Xu, J., Gong, J.B. and Cheng, Y. (2012) Protective effect of ligustrazine against myocardial ischaemia reperfusion in rats: The role of endothelial nitric oxide synthase. Clinical and Experimental Pharmacology and Physiology, 39, 20-27. doi:10.1111/j.1440-1681.2011.05628.x

[14] Dweik, R.A. (2001) The promise and reality of nitric oxide in the diagnosis and treatment of lung disease. Cleveland Clinic Journal of Medicine, 68, 486-490. doi:10.3949/ccjm.68.6.486

[15] Careau, E., Sirois, J. and Bissonnette, E.Y. (2002) Characterization of lung hyperresponsiveness, inflammation, and alveolar macrophage mediator production in allergy resistant and susceptible rats. American Journal of Respiratory Cell and Molecular Biology, 26, 579-586.

[16] Aiko, O. (2002) Pulmonary nitric oxide in preterm and term infants with respiratory failure. Act Universitatis Ouluensis Medica, Oulu University Press, Oulu, 74.

[17] Adler, K.B., Fischer, B.M., Li, H., Chloe, N.H. and Wright, D.T. (1995) Hyper secretion of cumin is response to inflammatory mediators by guinea pig tracheal epithelial cells in vitro is blocked by inhibition of nitric oxide syntheses. American Journal of Respiratory Cell and Molecular Biology, 13, 526-530. doi:10.1152/physrev.00034.2003

[18] Ricciardolo, F.L.M., Sterk, P.J., Gaston, B. and Folkerts, G. (2004) Nitric oxide in health and disease of the respiratory system. Physiological Research, 84, 731-765.

[19] Dijkstra, G., van Goor, H., Jansen, P.L. and Moshage, H. (2004) Targeting nitric oxide in the gastrointestinal tract. Current Opinion in Investigational Drugs, 5, 529-536.

[20] Russo, A., Fraser, R., Adachi, K., Horowitz, M. and Boeckxstaens, G. (1999) Evidence that nitric oxide mechanisms regulate small intestinal motility in humans. Gut, 44, 72-76. doi:10.1136/gut.44.1.72

[21] Stark, M.E. and Szurszewski, J.H. (1992) Role of nitric oxide in gastrointestinal and hepatic function and disease. Gastroenterology, 103, 1928-1949.
[22] Stanek, A., Gadowska-Cicha, A., Gawron, K., Wielkoszynski, T., Adamek, B., Gieslar, G., Wiczkowski, A. and Sieron, A. (2008) Role of nitric oxide in physiology and phatology of the gastrointestional tract. Mini-Reviews in Medicinal Chemistry, 8, 1549-1560. doi: $10.2174 / 138955708786786462$

[23] Sharma, S.P. (2004) Nitric oxide and the kidney. Indian Journal of Nephrology, 14, 77-84.

[24] Baylis, C.H. (2008) Nitric oxide deficiency in chronic kidney disease. American Journal of Physiology-Renal Physiology, 294, F1-F9. doi:10.1152/ajprenal.00424.2007

[25] Sugino, N., Takiguci, S., Ono, M., Tamura, H., Shimamura, K., Nakamura, Y., Tsuruta, R., Sadamitsu, D., Ueda, T., Maekawa, T. and Kato, H. (1996) Nitric oxide concentration in the follicular fluid and apoptosis of granulosa cells in human follicles. Human Reproduction, 11, 2484-2487. doi:10.1093/oxfordjournals.humrep.a019144

[26] Magness, R.R., Shaw, C.E., Pherretton, T.M., Zheng, J. and Bird, I.M. (1997) Endothelial vasodilator production by uterine and systemic arteries. II. Pregnancy effects on NO synthase expression. American Journal of Physiology, 272, H1730-H1740.

[27] Momohara, Y., Sakamoto, S., Obayashi, S., Aso, T., Goto, M. and Azuma, H. (2004) Roles of endogenous nitric oxide synthase inhibitors and endothelin-1 for regulating myometrial contractions during gestation in the rat. Molecular Human Reproduction, 10, 505-512. doi:10.1093/molehr/gah072

[28] Rosselli, M., Keller, P.J. and Dubey, R.K. (1998) Role of nitric oxide in the biology, physiology and pathophysiology of reproduction. Human Reproduction Update, 4, 324. doi:10.1093/humupd/4.1.3

[29] Davidoff, M.S., Middendorff, R., Mayer, B., de Vente, J., Koesling, D. and Holstein, A.F. (1997) Nitric oxide/ cGMP pathway components in the Leydig cells of the human testis. Cell Tissue, 287, 161-170. doi: $10.1007 / \mathrm{s} 004410050742$

[30] Bogdan, C. (2001) Nitric oxide and the immune response. Nature Immunology, 2, 907-916. doi:10.1038/ni1001-907

[31] Karpuzoglu, E. and Ahmed, S.A. (2006) Estrogen regulation of nitric oxide and inducible nitric oxide synthase (iNOS) in immune cells: Implications for immunity, autoimmune diseases, and apoptosis. Nitric Oxide, 15, 177186. doi:10.1016/j.niox.2006.03.009 